\title{
Morphometric Analysis and Immunocytochemical Staining on Cytospin Preparation in Effusion Cytology: A Study
}

Rajeev Sen ${ }^{1}$, Sonia Hasija ${ }^{2 *}$, Rajnish Kalra', Shilpa Garg' ${ }^{2}$, Ajeet Singh ${ }^{3}$ and Megha ${ }^{1}$

${ }^{1}$ Department of Pathology, PGIMS Rohtak, Haryana, India

${ }^{2}$ Department of Pathology, SHKM, GMC, Nalhar, Mewat, Haryana, India

${ }^{3}$ Department of Pulmonary and Critical Care Medicine PGIMS Rohtak, Haryana, India

\begin{abstract}
Introduction: Morphological differentiation between reactive mesothelial proliferation and metastatic carcinoma cells may be extremely difficult in conventional centrifuge deposit smears stained with papanicolaou and romanowsky dyes. In the present study immunocytochemistry and morphometric analysis were performed on cytospin preparation of effusion categorized as atypical/suspicious on toluidine blue stained wet films.
\end{abstract}

Materials and methods: A total of 100 cases comprising 26 benign (control group) and 74 malignant (study group) effusions were included in the study. Samples showing atypical /suspicious cells on preliminary conventional centrifuged wet film stained with toluidine blue; 63 were aspirated from pleural, 36 from peritoneal and 1 from pericardial effusions. These samples were processed for 6 cytospin preparations, 1 air dried stained with giemsa and others fixed in ethanol stained with papnicolaou stain, Cytokeratin 8/18, Epithelial Membrane Antigen (EMA) and Calretinin. Morphometric analysis was performed using software Image Pro Plus Version 6.3 on a minimum of 20 positive and negative stained cells on IHC stained smears.

Results: The sensitivity and specificity of CK $8 / 18$ in diagnosing benign, atypical and malignant cases were $91.89 \%$ and $89.5 \%$ respectively. The sensitivity and specificity of EMA was $90.5 \%$ and $86.6 \%$ respectively. Calretinin had $97 \%$ sensitivity for mesothelial cells. The 3 negative cases did not express CK 8/18 and EMA also. Thus, Calretinin can be accepted as a technique control to decide that immunocytochemical staining is working in a given case because mesothelial cells are generally present in benign as well as malignant effusions as native exfoliated cells. Nuclear area, cytoplasmic area and N:C ratio of mesothelial cells in benign effusions were $56.2 \pm 2.03 \mathrm{um}^{2}$, $182.41 \pm 4.61 \mathrm{um}^{2}$ and $0.31 \pm 0.01 \mathrm{um}^{2}$ and in malignant effusions were $63.15 \pm 2.44 \mathrm{um}^{2}, 185.67 \pm 2.15 \mathrm{um}^{2}$ and $0.34 \pm 0.01 \mathrm{um}^{2}$ respectively. Using ROC (Receiver Operating Characteristic) curve nuclear area $88.30 \mu \mathrm{m}^{2}$ area [sensitivity $(98.6 \%)$ and specificity $(94 \%)$ ] cytoplasmic area $200.55 \mu \mathrm{m}^{2}$ area [sensitivity $(100 \%)$ and specificity $(90 \%)$ ] and $\mathrm{N}: \mathrm{C}$ ratio 0.345 [sensitivity (93\%) and specificity (94\%)] considered as cut off values. So, we can use this value to discriminate between reactive mesothelial proliferations from malignant cells.

Conclusion: IHC can be easily performed on cytospin preparation without requiring antigen retrieval and is extremely useful in differentiating metastasis from reactive mesothelial proliferation. The results of morphometric analysis were useful adjunct.

Keywords: Mesothelioma;Immunocytochemistry; Adenocarcinoma; Computerized-interactive morphometric; Calretinin; Cytokeratin and epithelial membrane antigen

\section{Introduction}

The presence of fluids $(>10 \mathrm{ml})$ within the three body cavities namely pleural, peritoneal and pericardial cavity constitutes an effusion which can be transudate or exudate [1].

Accumulation of transudate is mostly due to decreased colloid osmotic pressure, sodium retention and circulatory disturbance such as venous outflow block. Exudative effusions can be caused by a variety of diseases like inflammation and malignant neoplasms. Benign cellular components contained in the serous effusion include macrophages and mesothelial cells. Malignant cells in serous effusion are mostly derived from adenocarcinoma and exhibit typical features of glandular cell types like globular, tubular, mucus secreting and single columnar [2].

The diagnosis of mesothelioma and adenocarcinoma requires the integration of the clinical history, radiographic findings, histomorphology, cytopathology and immunohistochemistry. In many cases, diagnosis cannot be reached based on morphology alone. Thus, the diagnostic accuracy of effusion cytology is enhanced through the utilization of ancillary techniques [3].
Immunocytochemistry (ICC) is a widely used tool to describe malignant cells in effusion [4]. Cytospins is advantageous in immunocytochemistry as there is lack of background staining. There is ease of interpretation since cells are concentrated in a small area. Multiple slides can be prepared and relatively small amount of antibodies or other reagents are used [5].

Morphometry by computer-aided image analysis can form a simple relatively less expensive and an effective diagnostic tool to sort out malignant cells by evaluation of various parameters especially nuclear and cytoplasmic variables of the "suspicious/atypical" cells. In fact, computerized-interactive morphometric (CIM) studies have been used

*Corresponding author: Sonia Hasija, Department of Pathology, SHKM, GMC, Nalhar, Mewat, Haryana, India, Tel: 91-9728141421; E-mail: drsoniahasija@gmail.com

Received December 20, 2014; Accepted February 18, 2015; Published February 20, 2015.

Citation: Sen R, Hasija S, Kalra R, Garg S, Singh A, et al. (2015) Morphometric Analysis and Immunocytochemical Staining on Cytospin Preparation in Effusion Cytology: A Study. J Cytol Histol 6: 314. doi:10.4172/2157-7099.1000314

Copyright: (C) 2015 Sen R, et al. This is an open-access article distributed under the terms of the Creative Commons Attribution License, which permits unrestricted use, distribution, and reproduction in any medium, provided the original author and source are credited. 
in terms of greater sensitivity and specificity for cytological evaluation of effusion samples [6].

Thus routine microscopic evaluation on effusion cytology many times is not able to discriminate between benign reactive mesothelial cells, atypical histiocytes and malignant cells due to overlapping morphological features. Therefore, the present study is planned to assess the utility of ancillary techniques of immunocytochemistry and image analysis in improving diagnostic accuracy in effusion cytology.

\section{Material and Methods}

The present study was conducted between December 2010 to 2012 in the Department of Pathology, Pt. B.D. Sharma, PGIMS, Rohtak. A total of 74 consecutive samples of effusion cytology showing atypical cells with adequacy of material and preservation of morphology irrespective of the age and sex, constituted the study material. Similarly, 26 samples negative for atypical cells constituted control group.

All the effusions cytology samples were subjected to conventional centrifuge preparation and one wet smear stained with alcoholic toluidine blue (1\%) [7] was examined to decide adequacy of material, preservation of morphology and diagnostic protocol to be followed. The effusion samples were subjected to conventional centrifuge deposit preparation and cytocentrifuged preparation [8]. The smears thus obtained were subjected to staining one with Romanowasky dye (Leishman Stain) and other with Haematoxylin and Eosin (HandE)/ Papanicolaou (Pap) stain as per standard techniques [9]. Additionally, a minimum of three cytospin smears were fixed in ethanol and preserved for immunocytochemical staining.

The smears stained were examined in detail and reported as positive for malignancy, suspicious/atypical favouring malignancy/atypical favouring reactive or benign. On the basis of cytomorphology study group was divided into I (containing suspicious cells) and II (containing malignant cells). Immunocytochemical profile were assessed on the ethanol fixed cytospin smears as per standard technique [5,9]. These cytospin smears were be subjected to Calretinin, Cytokeratin (CK) and EMA to discriminate between mesothelial cells and carcinoma.

Primary and secondary antibodies (CK 8/18, EMA and Calretinin) were procured from BioGenex (BioGenex laboratories, California, USA). For staining the protocol given by BioGenex was followed with modification (antigen retrival step was omitted) for its application for cytological smears.

\section{Cytocentrifuge/cytospin}

Cytospin is useful in the preparation of specimen with a very small amount of sample [9]. Ideally, cytospin should be a monolayer of cells with a minimum of 100 tumor cells per slide [10]. Cytospins are advantageous in immunocytochemistry as there is lack of background staining. There is ease of interpretation since cells are concentrated in a small area. Multiple slides can be prepared and relatively small amount of antibodies or other reagents are used [5].

The cytospin technique is known to stretch and distort cellular and nuclear morphology and allow nucleoli to appear more prominent than what one would normally see in peripheral smears. Cytospinning, however, does not change $\mathrm{N}: \mathrm{C}$ ratios nor does it alter relative chromatin textures or clumping patterns. Though this technique can make cells appear larger that on the peripheral blood smear, it cannot change cytoplasmic textures and granulation. Focusing on these steadfast features can make cytospin morphology less intimidating.

\section{Morphometric analysis}

The quantitative morphometric studies were done by image analysis. Images provided by charged device video camera coupled with Olympus BX 51 microscope at a magnification 200X were stored on host computer based on Pentium 4 processor with operating Microsoft windows vista through digital frame grabber and processing was done by image analyzer software Microsoft image pro-plus version 6.3. Area on slide to be imaged was visually selected. Random cell clusters were selected, excluding any damaged cell cluster. Measurements were performed with $20 \mathrm{X}$ objective magnification which when added to the 10X video ocular resulted in an image magnification of $200 \mathrm{X}$ on monitor screen. Nuclear area, cytoplasmic area and N: C ratio was calculated. 20 stained cells (brown) by IHC were analysed cell by cell in the cell clusters with the software. Then average of these was taken.

The morphometric values of mesothelial cells in benign and malignant effusions were compared. These values were also compared with malignant cells using t- test. Finally using Receiver Operating Characterstic (ROC) curve, a cut off value was obtained to decide whether that this ancillary technique could be used as a screening test.

Also, correlations of nuclear area and cytoplasmic area of mesothelial cells in benign effusions and nuclear area and cytoplasmic area of malignant cells in malignant effusions was done using pearson's coefficient.

\section{Interpretation and statistical analysis}

Stained smears were examined for specific cytological features and correlated with morphometric parameters and compared with final diagnosis, taking ICC and clinical diagnosis as gold standard. The sensitivity, specificity were calculated after cytomorphology and after ICC.

Finally, results of the immunocytochemical staining on cytospin preparation and morphometric analysis was compared in terms of enhancing diagnostic accuracy of initial cytomorphological observations. All the data obtained was subjected to statistical analysis by appropriate methods (paired and unpaired t test).

\section{Observations and Results}

A total of 100 cases comprising 26 benign (control group) and 74 malignant (study group) effusions were included in the study. There were 63 cases of pleural effusions, 36 of peritoneal and 1 of pericardial effusions. Males had a higher proportion of pleural effusions (34\%) compared to females (29\%) whereas females had a higher proportion of peritoneal effusions (30\%) as compared to males (6\%) (Figure 1).

Table 1 illustrate the causes of effusion in control group. Overall, tuberculosis was the underlying cause for benign effusion in 12 cases (46.5\%). Out of which 8 were macroscopically serofibrinous and 2 were haemorrhagic. Tuberculosis was the main aetiology agent causing pleural effusion in 9 cases and peritoneal effusion in 3 cases. After that pyogenic effusion was found in 9 cases $(34.6 \%)$. Two cases $(7.69 \%)$ of CHF (congestive heart failure) presented as pleural effusion. Least common cause was pneumonitis, found only in 1 case $(3.84 \%)$. The cause of effusion was unknown in 2 cases (7.69\%), one was pleural and one was peritoneal (Figure 2).

Table 2 illustrates the causes of effusions in study group on the basis of clinical diagnosis. Out of 74 cases, carcinoma lung was the most common cause of malignant effusion in males i.e. 16 cases $(21.67 \%), 14$ cases in females (18.91\%) and carcinoma ovary was the most common 


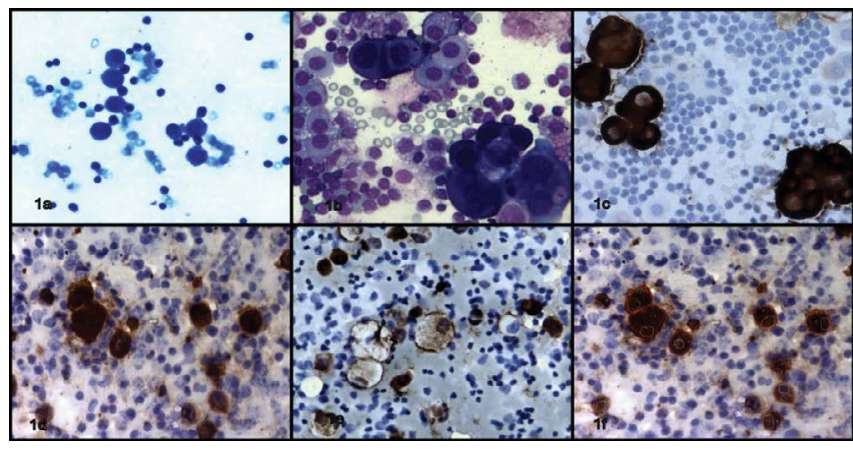

Figure 1: a) Cluster of suspicious cells, mesothelial cells and lymphocytes. (toluidine 100X), b) Cluster of malignant cells, mesothelial cells and lymphocytes. (Leishman 100X), C) Cluster of suspicious cells, showing cytoplasmic positivity (IHC CK: 200X), d) Cluster of suspicious cells, showing cytoplasmic and membranous cytoplasmic positivity (IHC EMA: 200X), e) Scattered mesothelial cells, showing cytoplasmic positivity. (IHC Calretinin: 200X), f) Morphometric analysis of singly CK positive cells. (IHC: 200X), finally diagnosed as lung carcinoma.

\begin{tabular}{|c|c|c|c|c|c|}
\hline Causes & $\begin{array}{c}\text { Pleural } \\
\text { effusions }\end{array}$ & $\begin{array}{c}\text { Peritoneal } \\
\text { effusions }\end{array}$ & Pericardial & $\begin{array}{c}\text { Total } \\
\text { cases }\end{array}$ & $\begin{array}{c}\text { Percentage } \\
\text { (\%) }\end{array}$ \\
\hline Tuberculosis & 9 & 3 & - & 12 & 46.15 \\
\hline Pyogenic & 6 & 3 & - & 9 & 34.6 \\
\hline CHF & 1 & - & 1 & 2 & 7.69 \\
\hline Pneumonitis & 1 & - & - & 1 & 3.84 \\
\hline Unknown & 1 & 1 & - & 2 & 7.69 \\
\hline Total & 18 & 7 & 1 & 26 & 100 \\
\hline
\end{tabular}

Table 1: Aetiology of effusions in control group (clinical diagnosis).

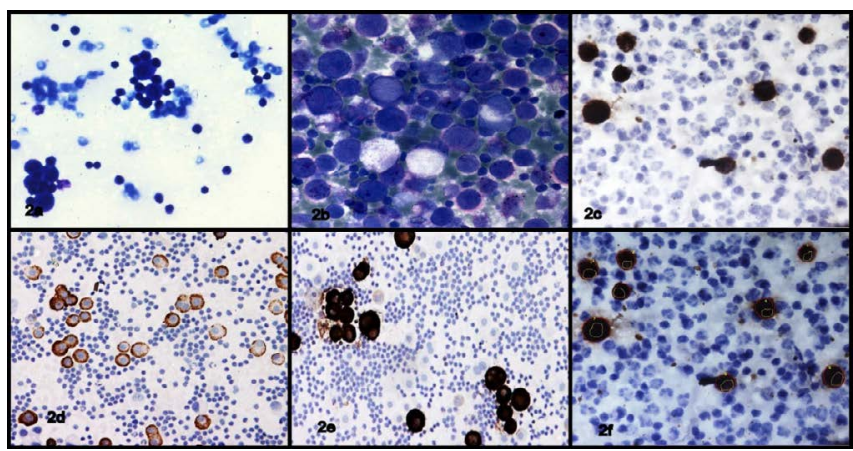

Figure 2: a) Cluster of suspicious cells, mesothelial cells and lymphocytes. (toluidine 100X), b) Cluster of malignant cells, mesothelial cells and lymphocytes. (Leishman 100X), c) Cluster of suspicious cells, showing cytoplasmic and nuclear positivity (IHC CK: 200X), d) Cluster of suspicious cells, showing membranous cytoplasmic positivity (IHC EMA: 200X), e) Scattered mesothelial cells, showing cytoplasmic and nuclear positivity. (IHC Calretinin: 200X), f) Morphometric analysis of singly CK positive cells. (IHC: 200X). Finally diagnosed as gall bladder carcinoma.

cause among females i.e. 22 cases (29.72\%). Four cases $(5.4 \%)$ had carcinoma breast and 2 cases $(2.70 \%)$ were of carcinoma gall bladder. The remaining 15 cases $(20.27 \%)$ were of malignancy from unknown primary.

Table 3 illustrates that the Study group was further subdivided on conventional cytomorphological examination, in group I, consist of 37 cases showing suspicious cells on conventional cytomorphology and group II, consist of 37 cases showing malignant cells on cytomorphology. The sensitivity and specificity of cytomorphological diagnosis are $52.11 \%$ and $89.65 \%$ respectively.
Immunocytochemical profiles were assessed on the ethanol fixed cytospin smears. These cytospin smears were be subjected to Calretinin, Cytokeratin (CK) and EMA to discriminate between mesothelial cells and carcinoma (Table 4).

In the present study Calretinin expression was observed in $97 \%$ cases. Calretinin staining is helpful in as much as its negativity as well as its positivity, it brings out negative stained malignant cells in sharp contrast to positive stained mesothelial cells. Its expression was mostly cytoplasmic (97\%) and in 3 cases it was both nuclear as well as cytoplasmic compared to IHC where only nuclear expression is considered specific.

After immunocytochemistry 29 cases were diagnosed as benign, 3 remain in the category of atypical/suspicious and 68 were malignant. Three cases which were considered atypical/suspicious (false negative) on ICC expression; their clinical course indicated malignant effusion and cytology and conventional cytomorphology showed highly suspicious cells. ICC increases the sensitivity and specificity $95.77 \%$ and $89.65 \%$ respectively (Table 5 ).

Using ROC curve nuclear area $88.30 \mu \mathrm{m}^{2}$ area [sensitivity (98.6\%) and specificity (94\%)] cytoplasmic area $200.55 \mu \mathrm{m}^{2}$ area [sensitivity $(100 \%)$ and specificity $(90 \%)$ ] and N:C ratio 0.345 [sensitivity $(93 \%)$ and specificity (94\%)] considered as cut off values. So, we can use this value to discriminate between reactive mesothelial proliferations from malignant cells.

Also, cytoplasmic area of mesothelial cells significantly increased proportional to nuclear area in benign effusions (Pearson Coefficient $=0.433, \mathrm{p}<0.05)$. Similarly, in malignant effusions the cytoplasmic area of malignant cells significantly increased proportional to nuclear area (Pearson Coefficient $=0.433, \mathrm{p}<0.05$ ) but cytoplasmic area of mesothelial cells did not significantly increased with nuclear area $($ Pearson Coefficient $=-0.318, \mathrm{p}<0.05)$.

Immunocytochemistry improved the diagnostic accuracy of effusion cytology as sensitivity increased from $52.11 \%$ to $91.89 \%$. Also, the cut off value of parameters used in morphometric analysis (nuclear area $88.3 \mathrm{um}^{2}$, cytoplasmic area $200.55 \mathrm{um}^{2}$ and $\mathrm{N}: \mathrm{C}$ ratio 0.34 ) were also useful in discriminating mesothelial proliferation from malignant cells. Finally the diagnosis is made on the basis of immunocytochemistry, morphometric analysis and clinical correlation.

\section{Discussion}

The involvement of serous cavities by malignant neoplasms has important therapeutic and prognostic implications. The diagnosis of metastatic cancer in pleural, peritoneal or pericardial fluids is of capital importance for the patient and the attending physician or surgeon. In most such instances, the rapid fatal outcome of the disease may be anticipated. However, with the use of appropriate therapy, some metastatic tumors offer a much better prognosis than others. For example, metastatic mammary carcinoma may be controlled, often for a period of several years, by means of hormonal manipulation or chemotherapy. Malignant lymphomas and some malignant tumors of childhood respond to energetic therapeutic measures. Therefore, the responsibility of the pathologist is to identify cancer cells accurately and to identify tumor type and if possible, the site of primary origin. The latter task is greatly facilitated by simultaneous review of histopathological material, if available and by an accurate clinical history.

Satisfactory evidence of cancer is as necessary in effusion as any other type of material before the diagnosis with all its potentially tragic 


\begin{tabular}{|c|c|c|c|c|}
\hline Causes & $\begin{array}{c}\text { Pleural } \\
\text { effusions }\end{array}$ & $\begin{array}{c}\text { Peritoneal } \\
\text { effusions }\end{array}$ & $\begin{array}{c}\text { Total } \\
\text { cases }\end{array}$ & $\begin{array}{c}\text { Percentage } \\
\text { (\%) }\end{array}$ \\
\hline Carcinoma lung & 30 & - & 30 & 40.54 \\
\hline Carcinoma ovary & 01 & 22 & 23 & 31.08 \\
\hline Carcinoma breast & 3 & 01 & 4 & 5.4 \\
\hline Carcinoma gall bladder & 2 & - & 2 & 2.7 \\
\hline Carcinoma tongue & 01 & - & 1 & 1.35 \\
\hline Unknown primary & 8 & 06 & 14 & 18.91 \\
\hline Total & 45 & 29 & 74 & 100 \\
\hline
\end{tabular}

Table 2: Aetiology of effusions in study group (clinical diagnosis).

\begin{tabular}{|c|c|c|c|}
\hline Clinical diagnosis & \multicolumn{2}{|c|}{ Cytomorphological category } & No of cases \\
\hline Benign & Benign & Control group & 26 \\
\hline \multirow{2}{*}{ Malignant } & Atypical/suspicious & Study group I & 37 \\
\cline { 2 - 4 } & Malignant & Study group II & 37 \\
\hline & Total & & 100 \\
\hline
\end{tabular}

Table 3: Distribution of cases according to cytomorphological diagnosis.

consequences is made. The use of impeccable technical preparations is of utmost importance in ensuring diagnostic accuracy. Effusions may present the cyto-pathologist with some of the most challenging of diagnostic dilemmas. It is because of the difficulty in distinguishing atypical mesothelial hyperplasia, mesothelioma and metastatic adenocarcinoma $[11,12]$. There are three types of preparations in general use: smears, cytospin preparations and histologic sections of the sediments (cell block technique) [12].

The cytospin process works by wicking fluid into a filter while fluids samples are spun into a central column and deposited in a mono-layer onto a defined area of a slide. This allows the cells to be concentrated for appropriate identification. This technique can bring pronounced changes to morphology and staining characteristics, as well as cellular destruction if the cytospin malfunctions. The cytospin technique is known to stretch and distort cellular and nuclear morphology and allow nucleoli to appear more prominent than what one would normally see in peripheral smears. Cytospinning, however, does not change $\mathrm{N}: \mathrm{C}$ ratios nor does it alter relative chromatin textures or clumping patterns [13]. Though this technique can make cells appear larger that on the peripheral blood smear, it does not change cytoplasmic textures and granulation. Focussing on these steadfast features can make cytospin morphology less intimidating [13].

Cell morphology, the mainstay of cytologic diagnosis, can be obscured by poor preservation of cells within the fluid. The reactive mesothelial cells may be extremely pleomorphic whereas some malignant cells may be deceivingly bland [12]. Various studies have shown a sensitivity of $57.3 \%$ and specificity of $89 \%$ by conventional cytology for the detection of malignant cells in effusion samples. Studies have shown that positive and negative predictive values for detection of malignancy by cytomorphology are $89.3 \%$ and $69.4 \%$ respectively. However, a grey zone always exists, where the cytopathologist encounters problems in determining the nature of the cells whether reactive, atypical or beyond doubt malignant. Therefore various ancillary techniques should be used to increase the diagnostic accuracy of malignancy in serous effusions like immunocytochemistry, electron microscopy, image morphometry etc [14].

Immunocytochemical methods have advantages and disadvantages over other methods used to gain similar diagnostic information. An important advantage in some cases is that cell morphology is preserved, thus the cells and their staining pattern may be observed and assessed simultaneously. Additionally, the fixation and processing techniques applied to cytologic specimens are usually "gentler" than those used in histopathologic specimens, resulting in greater antigen preservation and therefore, applicability of a broader range of antibodies for ICC versus immunohistochemistry [15].

We have our observations and the results, from the current study conducted between 2011-2013 in our department on 100 patients with effusion in body cavities with aim to correlate immunocytochemistry and morphometric analysis in improving diagnostic accuracy in effusion cytology. Morphological differentiation between reactive mesothelial proliferation and malignant cells may be extremely difficult in conventional centrifuge deposit smears stained with Papanicolaou and Romanowasky dyes. It cannot be overemphasized that there is no single architectural, nuclear or cellular parameter that can reliably and reproducibly differentiate between the two.

According to the clinical diagnosis, out of 100 cases studied, 26 were benign (control group), 74 were suspicious for malignancy (study group). Finally on the basis of immunocytochemistry and morphometry $71 \%$ of exudative effusions were secondary to malignancy. There were 63 cases of pleural effusions, 36 of peritoneal and 1 of pericardial effusions. Tuberculosis accounted for $50 \%$ of pleural effusions and $42.8 \%$ of peritoneal effusions of the current series as compared to $20.24 \%$ reported by Gasper et al. [15] in pleural effusions and $9 \%$ by Mahmood et al. [16] in peritoneal effusions. The difference in the incidence of etiology between findings of the present series and those of Gasper are explained on the basis of differences in the incidence of infections in community and also patients of pneumonitis are generally not subjected to aspiration in India.

Out of 74 cases of malignant effusions, carcinoma lung was the most common cause of malignant effusion in males (21.67\%) followed by carcinoma gall bladder (2.7\%); in females carcinoma ovary $(31.08 \%)$ was the most common cause followed by carcinoma lung $(17.56 \%)$ and breast $(4.05 \%)$. The remaining 14 cases $(18.9 \%)$ were of metastasis of unknown primary.

Carcinoma lung and carcinoma ovary are the commonest malignancies in pleural and peritoneal effusions respectively irrespective of geographical location and index of development [15,17].

Smears from exudates are generally cellular, whereas transudates generally show low cellularity. The cellularity may be contributed by mesothelial cells, inflammatory cells and metastatic cells. Out of total of 100 cases, definite distinction between benign and malignant could not be achieved in 37 cases which were cytomorphological equivocal on conventional staining (HandE/Leishman) of centrifuge deposits as well as cytocentrifuge preparation. Marked cytomorphological atypia was considered definitive diagnosis of malignancy in 3 cases which actually turned out to be benign on ICC and morphometry. Thus sensitivity and specificity in the present study was $52.11 \%$ and $89.65 \%$ respectively.

\section{Immunocytochemistry analysis}

The advent of immunocytochemistry has led to a great improvement in the accuracy of cytopathology of serous effusions during the last two decades. Numerous monoclonal and polyclonal antibodies reactive with mucosubstances, oncofetal antigens, carbohydrates, sugar residues, and intermediate filaments are now available. Commonly used antibodies in the differentiation of malignant cells from reactive mesothelial cells are CK, EMA, CEA, Leu M1, B72.3, BerEP4, CA 199, HMB45 [18]. Cell blocks may not contain enough number of cells, time consuming and the proteinaceous material gives background staining. Therefore, cytospin preparation method was adopted. 


\begin{tabular}{|c|c|c|c|c|c|}
\hline & $\begin{array}{l}\text { control group } \\
\text { (benign) }\end{array}$ & $\begin{array}{l}\text { study group-1 } \\
\text { (suspicious) }\end{array}$ & $\begin{array}{c}\text { study group-2 } \\
\text { (malignant) }\end{array}$ & sensitivity & Specificity \\
\hline Cytomorphology & 26 & 37 & 37 & $52.11 \%$ & $89.65 \%$ \\
\hline \multicolumn{6}{|c|}{ Cytokeratin } \\
\hline Nuclear & - & - & - & \multirow{4}{*}{$91.89 \%$} & \multirow{4}{*}{$89.5 \%$} \\
\hline Cytoplasmic & - & 29 & 32 & & \\
\hline \multirow[t]{2}{*}{ both } & - & 3 & 4 & & \\
\hline & & 32 & 36 & & \\
\hline \multicolumn{6}{|c|}{ EMA } \\
\hline cytoplasmic & - & 28 & 28 & \multirow{3}{*}{$90.5 \%$} & \multirow{3}{*}{$86.6 \%$} \\
\hline membranous & - & 3 & 3 & & \\
\hline both & - & 1 & 4 & & \\
\hline \multicolumn{6}{|c|}{ Calretinin } \\
\hline Only nuclear & - & - & - & \multirow{3}{*}{$97 \%$} & \\
\hline Only cytoplasmic & 24 & 33 & 37 & & \\
\hline both & 2 & 1 & - & & \\
\hline
\end{tabular}

Table 4: Expression of cytokeratin (CK 8/18), EMA, and Cytokeratin.

\begin{tabular}{|c|c|c|c|c|c|}
\hline & \multicolumn{2}{|c|}{ Mesothelial cells } & \multicolumn{2}{|c|}{ Malignant cells } & \multirow{2}{*}{$P$ value } \\
\hline & Range & Mean \pm S.D. & Range & Mean \pm S.D. & \\
\hline Nuclear area & $58.1-68.8 u^{2}$ & $63.15 \pm 2.44 u^{2}{ }^{2}$ & 86.4- 130.7 um$^{2}$ & $108.07 \pm 12.65 u^{2}$ & $P<0.001$ \\
\hline Cytoplasmic area & $182.4-190.6 u^{2}$ & $185.67 \pm 2.15 u^{2}$ & 212.6- 297. $2 u^{2}$ & $263.03 \pm 19.2 u^{2}$ & $P=0.677$ \\
\hline $\mathrm{N}: \mathrm{C}$ ratio & $0.31-0.37$ & $0.34 \pm 0.014$ & $0.31-0.5$ & $0.41 \pm 0.04$ & $P<0.001$ \\
\hline
\end{tabular}

Table 5: Comparison of morphometric values of mesothelial cells and malignant cells in study group.

Positive staining with at least two adenocarcinoma markers would favour the diagnosis. In the present study the sensitivity and specificity of CK 8/18 in diagnosing benign, atypical and malignant cases were $91.89 \%$ and $89.5 \%$ respectively. The sensitivity and specificity of EMA in diagnosing benign, atypical and malignant cases were $90.5 \%$ and $86.6 \%$ respectively.

Calretinin expression was observed in 97 out of a total of 100 cases included in the present study. The 3 negative cases did not express $\mathrm{CK}$ and EMA also. Thus, calretinin can be accepted as a technique control to decide that immunocytochemical staining is working in a given case because mesothelial cells are generally present in benign as well as malignant effusions as native exfoliated cells. The three cases among suspicious group were negative for CK, EMA and Calretinin also. A stepwise approach may remote suiTable with first step designed to differentiate mesothelial proliferations and histiocytes from metastasis and subsequent steps to diagnose the histological type of malignancy and its primary site (Table 6).

\section{Morphometric analysis}

In the present study nuclear area, cytoplasmic area and $\mathrm{N}: \mathrm{C}$ ratio were performed on true one mesothelial cells staining positive for calretinin and metastatic epithelial cells stained positive for cytokeratin to find out that morphometric analysis could be useful in differentiating proliferative mesothelial cells from metastatic carcinoma. Reactive mesothelial proliferation resulted in statistically increased nuclear area, cytoplasmic area and $\mathrm{N}: \mathrm{C}$ associated with malignancy as compared to reactive mesothelial proliferation of inflammatory pathology $(\mathrm{p}<0.05)$. Nuclear area, cytoplasmic area and $\mathrm{N}: \mathrm{C}$ ratio of mesothelial cells in benign effusions were $56.2 \pm 2.03 \mathrm{um}^{2}, 182.41 \pm 4.61 \mathrm{um}^{2}$ and $0.31 \pm$ $0.01 \mathrm{um}^{2}$ and in malignant effusions were $63.15 \pm 2.44 \mathrm{um}^{2}, 185.67 \pm$ $2.15 \mathrm{um}^{2}$ and $0.34 \pm 0.01 \mathrm{um}^{2}$ respectively.

Also, significant difference were noticed between nuclear area and $\mathrm{N}: \mathrm{C}$ ratio of mesothelial cells and malignant cells $(\mathrm{p}<0.001)$ but the difference in cytoplasmic area was not statistically significant $(\mathrm{p}=0.677)$. Nuclear area and N:C ratio of mesothelial cells were 63.15 $\pm 2.44 \mathrm{um}^{2}$ and $0.34 \pm 0.014 \mathrm{um}^{2}$ respectively and malignant cells were $0.34 \pm 0.014 \mathrm{um}^{2}$ and $0.41 \pm 0.04 \mathrm{um}^{2}$ respectively.

Therefore, IHC and Morphometry like ancillary techniques are very beneficial in diagnosing metastasis in effusion and to differentiate it from reactive mesothelial proliferations.

ROC curve values were calculated, to find out most useful values of nuclear area, cytoplasmic area and $\mathrm{N}: \mathrm{C}$ ratio to discriminate between reactive mesothelial proliferation from malignant cells. At ROC curve value of nuclear area $88.3 \mu \mathrm{m}^{2}$, sensitivity and specificity was $98.6 \%$ and $94 \%$ respectively, at cytoplasmic area $200.55 \mu \mathrm{m}^{2}$, sensitivity and specificity was $100 \%$ and $90 \%$ respectively and N:C ratio 34.5 , sensitivity and specificity was $93 \%$ and $94 \%$ respectively. Thus, these values in this limited study were useful parameters for screening purposes to reduce the number of equivocal results [19-21].

The choice of panel of immunostaining enhances the diagnostic accuracy of effusion cytology in definitely differentiating reactive mesothelial cells from malignant cells. Image morphometry, although cumbersome, could still be useful in cases, where limited material is available and ICC cannot be able to perform either due to nonavailability of further material or absence of expression of antibodies.

\section{Conclusion}

To conclude, Pathologist's eye, experience, knowledge are still indispensable in discriminating between benign and malignant effusions. Conventional cytocentrifuge examination still remains the main stay for effusion diagnostics and to decide the choice of ancillary techniques. Cytocentrifuge preparations to be subjected for Romanowasky (Leishman Stain)/Haematoxylin and Eosin (HandE)/ Papanicolaou (Pap) staining and choice of panel of immunostaining enhance the diagnostic accuracy of effusion cytology in definitely differentiating reactive mesothelial cells from malignant cells. Image 
Citation: Sen R, Hasija S, Kalra R, Garg S, Singh A, et al. (2015) Morphometric Analysis and Immunocytochemical Staining on Cytospin Preparation in Effusion Cytology: A Study. J Cytol Histol 6: 314. doi:10.4172/2157-7099.1000314

Page 6 of 6

\begin{tabular}{|c|c|c|c|c|c|}
\hline & & Motherby et al. [20] & Saad et al. [21] & Metzgeroth et al. [22] & Present study \\
\hline \multirow{2}{*}{ Cytomorphology } & Sensitivity & $57.3 \%$ & & $84 \%$ & $52.11 \%$ \\
\hline & Specificity & $89 \%$ & & $92 \%$ & $89.65 \%$ \\
\hline \multirow{2}{*}{ Immunocytochemistry } & Sensitivity & & $75 \%$ & $94 \%$ & $95.77 \%$ \\
\hline & Specificity & & $100 \%$ & $100 \%$ & $89.65 \%$ \\
\hline
\end{tabular}

Table 6: Cytomorphology vs ICC.

morphometry, although cumbersome could still be useful in cases, where limited material is available.

\section{References}

1. Koss LG (2006) Effusions in the absence of cancer. In: Koss diagnostic cytology and its histopathologic bases (5thedn). Lippincott willams and Wilkins, New York, USA.

2. Takahashi M (1981) Color atlas of cancer cytology (2ndedn). George Thieme Verlag, Stuttgart, New York, USA.

3. Ylagan LR, Zhai $\mathrm{J}(2005)$ The value of thin prep and cytospin preparation in pleural effusion cytological diagnosis mesothelioma and adenocarcinoma. Diagn Cytopathol 32: 137-144.

4. Dejmek JS, Dejmek A (2006) The reactivity to CK5/6 antibody in tumor cells from non-small cell lung cancers shed into pleural effusions predicts survival. Oncol Rep 15: 583-587.

5. Koss LG (2006) Laboratory Techniques. In: Koss diagnostic cytology and its histopathologic bases. (5thedn) Lippincott Willams and Wilkins, New York, USA.

6. Arora B, Setia S, Rekhi B (2006) Role of computerized morphometric analysis in diagnosis of effusion specimens. Diagn Cytopathol 34: 670-675.

7. Naylor B (2008) Pleural, peritoneal and pericardial effusions. In: Comprehensive Cytopathology (3rdedn). Saunders, Philadelphia, USA.

8. Frable WJ (2008) Fine needle aspiration biopsy techniques. In: Comprehensive Cytopathology (3rdedn). Saunders, Philadelphia, USA.

9. Jackson P, Blythe D (2008) Diagnostic cytopathology: Specimen collection and preparation. In: Theory and practice of histological techniques (6thedn). Churchill Livingstone, Philadelphia, USA.

10. Fetsch PA, Abati A (2001) Immunocytochemistry in effusion cytology: a contemporary review. Cancer 93: 293-308.
11. Duggan MA, Masters CB, Alexander F (1987) Immunohistochemica differentiation of malignant mesothelioma, mesothelial hyperplasia and metastatic adenocarcinoma in serous effusions, utilizing staining for Carcinoembryonic antigen, Keratin and Vimentin. Actacytol 3: 807-814.

12. Rosen-Levin E, Patil JR, Watson CW, Jagirdar J (1989) Distinguishing benign from malignant pleural effusions by lectin immunocytochemistry. Acta Cytol 33 : 499-504.

13. http://www.medialabinc.net/spg374340/peripheral_morphology_vs_cytospin_ morphology.aspx

14. Mohanty SK, Dey P (2003) Serous effusions: diagnosis of malignancy beyond cytomorphology. An analytic review. Postgrad Med J 79: 569-574.

15. Gaspar MJ, Miguel JDE, García díaz JD, Diez M (2008) Clinical Utility of a Combination of Tumour Markers in the Diagnosis of Malignant Pleural Effusions. Anticancer research 28: 2947-2952.

16. Mahmood G, Debnath CR, Mandal AK (2009) Evaluation of 100 cases of ascites. Mymensingh Med J 18: 62-66.

17. Ayantunde AA, Parsons SL (2007) Pattern and prognostic factors in patients with malignant ascites: a retrospective study. Ann Oncol 18: 945-949.

18. Järvi OH, Kunnas RJ, Laitio MT, Tyrkkö JE (1972) The accuracy and significance of cytologic cancer diagnosis of pleural effusions. (A followup study of 338 patients). Acta Cytol 16: 152-158.

19. Motherby H, Nadjari B, Friegel P, Kohaus J, Ramp U, et al. (1999) Diagnostic accuracy of effusion cytology. Diagn Cytopathol 20: 350-357.

20. Saad RS, Cho P, Liu YL, Silverman JF (2005) The value of epithelial membrane antigen expression in separating benign mesothelial proliferation from malignant mesothelioma: a comparative study. Diagn Cytopathol 32: 156-159.

21. Metzgeroth G, Kuhn C, Schultheis B, Hehlmann R, Hastka J (2008) Diagnostic accuracy of cytology and immunocytology in carcinomatous effusions. Cytopathology 19: 205-211. 